\title{
Hypoxia promotes stem-like properties of laryngeal cancer cell lines by increasing the $\mathrm{CD} 133^{+}$stem cell fraction
}

\author{
CHUN-PING WU ${ }^{1 *}$, HUAI-DONG DU ${ }^{1 *}$, HONG-LI GONG ${ }^{1}$, DA-WEI LI ${ }^{1}$, LEI TAO ${ }^{1}$, JIE TIAN ${ }^{2}$ and LIANG ZHOU ${ }^{1}$ \\ ${ }^{1}$ Department of Otolaryngology-Head and Neck Surgery, Eye, Ear, Nose and Throat Hospital of Fudan University; \\ ${ }^{2}$ Research Center, Eye, Ear, Nose and Throat Hospital of Fudan University, Shanghai 200031, P.R. China
}

Received December 15, 2013; Accepted January 30, 2014

DOI: $10.3892 /$ ijo.2014.2307

\begin{abstract}
Evidence indicates that a hypoxic microenvironment plays an essential role in the regulation of cancer stem cells (CSCs). However, whether hypoxia is able to regulate the stem-like biological properties of laryngeal cancer cells remains unknown. In this study, we investigated the influence of hypoxia on the stemness of two laryngeal cancer cell lines, Hep-2 and AMC-HN-8. We cultured the two cell lines under hypoxia and normoxia and examined the influence of hypoxia on the expression of hypoxia-inducible factors (HIFs) and the cancer stem-like properties of these cells, including cell cycle distribution, expression of stem cell genes (OCT4, SOX2 and NANOG) and laryngeal CSC surface marker (CD133), proliferation, invasion, colony formation and sphere formation capacity. We determined that both of these cell lines, when maintained under hypoxic conditions, showed expanded cells in the G0/G1 phase, exhibited preferential expression of stem cell genes and CD133, and manifested upregulation of HIFs. When treated with hypoxia followed by normoxia exposure, the two cell lines exhibited enhanced capacities for proliferation, invasion, and sphere and colony formation compared with cells maintained consistently under normoxia. Our findings indicate that a hypoxic microenvironment may upgrade the stem-like biological properties of laryngeal cancer cell lines by the expansion of the $\mathrm{CD}_{133^{+}}$stem cell fraction.
\end{abstract}

\section{Introduction}

Until recently, cancer stem cells (CSCs) have been identified in multiple solid tumors, represented by $\mathrm{CD} 44^{+} / \mathrm{CD} 24$

Correspondence to: Professor Liang Zhou, Department of Otolaryngology-Head and Neck Surgery, Eye, Ear, Nose and Throat Hospital of Fudan University, 83 Fen Yang Road, Shanghai 200031, P.R. China

E-mail: zhoulent@126.com

*Contributed equally

Key words: hypoxia, tumor microenvironment, hypoxia-inducible factors, neoplastic stem cells, cell biology, laryngeal neoplasm breast cancer cells and CD133+ brain tumor cells (1-3). However, the ways in which CSCs are maintained and regulated remains to be discovered. Increasing evidence demonstrates that CSCs are protected and regulated by a specialized tumor microenvironment niche, which plays a crucial role in the maintenance of the CSC biological properties, including self-renewal, differentiation, invasion, metastasis, therapeutic resistance, and genetic instability (4-6). Although the CSC niche is still poorly understood, components of the niche have been shown to dominate CSC maintenance and one of the most important components is hypoxia.

Similar to the ways in which hypoxia maintains the physiological functions of normal stem cells (7), recent advances have shown that hypoxic stress also plays a critical role in the maintenance of CSCs in solid tumors (8-10). Research into breast cancer shows that hypoxic tumors induced by anti-angiogenic agents contain a significantly higher percentage of CSCs (11), and prostate cancer data indicate that prostate cancer cells under hypoxic conditions possess greater stem-like properties (12). Ovarian cancer cells under hypoxia upgrade their stem-like properties through the upregulation of stemness-related factors and behave more aggressively when returned to a higher oxygen environment (13). Similarly, hypoxia maintains the undifferentiated state of primary glioma cells, slows down their growth to a relatively quiescent stage, increases their colony forming efficiency and migration, and elevates the expression of stem cell markers (14).

As one of the most common malignancies of the head and neck region, laryngeal cancer is frequently encountered with hypoxic stress. Our previous investigations have identified CD133 as one of the CSC markers of laryngeal cancer, and demonstrated that $\mathrm{CD} 133^{+}$laryngeal cancer cells harbored more stem-like properties than CD133- subpopulation (15-17), indicating that laryngeal cancer also contains a CSC subpopulation. However, whether hypoxia can regulate the stem-like biological properties of laryngeal cancer cells remains unknown; therefore, we investigated the influence of hypoxia on the stemness of laryngeal cancer cells. Our findings demonstrate that hypoxia upgrades the stem-like biological properties of laryngeal cancer cell lines by increasing the $\mathrm{CD}_{133^{+}}$stem cell fraction, and the most likely mechanism is discussed. 


\section{Materials and methods}

Cell lines and cell culture. The human laryngeal cancer cell lines, Hep-2 and AMC-HN-8, were obtained from the Cell Bank of Type Culture Collection at the Chinese Academy of Sciences (CBTCCCAS, Shanghai, China). Unless otherwise noted, the cells were maintained in Dulbecco's modified Eagle's medium (DMEM) (Invitrogen, Grand Island, NY, USA), supplemented with $10 \%$ fetal bovine serum (FBS) (Invitrogen) and 1\% penicillin/streptomycin (Invitrogen). For normoxic cell culture, the cells were maintained in a humidified incubator in an atmosphere of $21 \% \mathrm{O}_{2}, 5 \% \mathrm{CO}_{2}$, and $74 \%$ $\mathrm{N}_{2}$ at $37^{\circ} \mathrm{C}$. For hypoxic cell culture, the ProOx $\mathrm{C} 21$ hypoxia cell culture chamber (BioSpherix, Lacona, NY, USA) was used to obtain the required atmosphere of $1 \% \mathrm{O}_{2}, 5 \% \mathrm{CO}_{2}$, and $94 \% \mathrm{~N}_{2}$ at $37^{\circ} \mathrm{C}$.

Flow cytometry. The Hep-2 and AMC-HN-8 cells cultured at $21 \%$ or $1 \% \mathrm{O}_{2}$ for $24 \mathrm{~h}$ were harvested and fixed dropwise with $70 \%$ ice-cold ethanol overnight at $4^{\circ} \mathrm{C}$. Then, RNase (Kayon, Shanghai, China) was added to the samples for a final concentration of $20 \mu \mathrm{g} / \mathrm{ml}$, and incubated for $30 \mathrm{~min}$ at $37^{\circ} \mathrm{C}$. This was followed by the addition of propidium iodide (Sigma, St. Louis, MO, USA) for a final concentration of $15 \mu \mathrm{mol} / 1$. The samples were filtered to acquire single-cell suspensions, and analyzed using an Aria II flow cytometer (Becton Dickinson, San Jose, CA, USA).

CD133 marker detection. The Hep-2 and AMC-HN-8 cells cultured at $21 \%$ or $1 \% \mathrm{O}_{2}$ for $48 \mathrm{~h}$ were harvested, and the phycoerythrin-conjugated CD133/1 (AC133) antibody (Miltenyi Biotech, Gladbach, Germany) was used to label CD133, since our previous investigations identified CD133 as one of the laryngeal CSC surface markers in the Hep-2 cell line (15-17). The incubation followed the protocol described by Chen et al (17), and the mouse IgG1 ( $\kappa)$ (eBioscience, San Diego, CA, USA) incubated under the same condition served as the isotypic control to exclude nonspecific staining. Samples were analyzed using the Epics Altra flow cytometer (Beckman Coulter, Fullerton, CA, USA).

Quantitative real-time polymerase chain reaction ( $q R T-P C R)$. At the time points of $6,12,24,48$ and $72 \mathrm{~h}$, the total RNA was extracted from the Hep- 2 and AMC-HN- 8 cells maintained at $1 \% \mathrm{O}_{2}$ by using the TRIzol ${ }^{\circledR}$ reagent (Invitrogen). Reverse transcription was performed using the PrimeScript ${ }^{\circledR}$ RT reagent kit with the gDNA Eraser (Takara, Dalian, China), and the qRT-PCR was done with the SYBR ${ }^{\circledR}$ Premix Ex Taq ${ }^{\mathrm{TM}}$ kit (Takara) in a Lightcycler 480 instrument (Roche Diagnostics, Rotkreuz, Switzerland). Thermal cycling included an initial denaturation at $95^{\circ} \mathrm{C}$ for $30 \mathrm{sec}$, followed by 40 cycles at $95^{\circ} \mathrm{C}$ for $5 \mathrm{sec}$ and $60^{\circ} \mathrm{C}$ for $30 \mathrm{sec}$. Cells maintained at $21 \% \mathrm{O}_{2}$ served as a control, while $\beta$-actin (ACTB) was used as an endogenous control. The formula $2^{-\Delta \Delta C T}$ was used to calculate the relative mRNA expression of $1 \% \mathrm{O}_{2}$ vs. $21 \% \mathrm{O}_{2}$. The primers used for amplification are listed in Table I.

Western blotting. The Hep-2 and AMC-HN-8 cells maintained at $1 \% \mathrm{O}_{2}$ were harvested at $6,12,24,48$, and $72 \mathrm{~h}$, while the cells maintained at $21 \% \mathrm{O}_{2}$ served as the control. Approximately $30 \mu \mathrm{g}$ of total protein from the lysates of Hep-2 and AMC-HN-8 cells was analyzed by electrophoresis using sodium dodecyl sulfate-polyacrylamide gel (Beyotime, Shanghai, China), electrotransferred to polyvinylidene fluoride membranes (Millipore, Billerica, MA, USA), and probed overnight with primary antibodies (Epitomics, Burlingame, CA, USA) for OCT4 (1:1,000; 2876-1), SOX2 (1:1,000; 2683-1), NANOG $(1: 1,000 ; 3369-1)$, HIF-1 $\alpha$ (1:1000; 2015-1), and HIF-2 $\alpha$ $(1: 1,000 ; 8551-1)$. Horseradish peroxidase-conjugated goat anti-rabbit IgG $(\mathrm{H}+\mathrm{L})(1: 10,000)$ (Jackson ImmunoResearch, West Grove, PA, USA) was then applied, followed by signal detection using BeyoECL Plus (Beyotime). The ACTB antibody (1:5,000; R1207-1) (HuaAn Biotechnology, Hangzhou, China) was used to normalize the amount of sample loaded.

Immunofluorescence staining. The Hep-2 and AMC-HN-8 cells maintained at $21 \% \mathrm{O}_{2}$ were harvested and replanted onto glass coverslips, and when they adhered to the dish, they were maintained at $21 \%$ or $1 \% \mathrm{O}_{2}$ for $48 \mathrm{~h}$. The cells were then fixed with $4 \%$ paraformaldehyde for $20 \mathrm{~min}$, and incubated in $1 \%$ bovine serum albumin/10\% normal goat serum/ $0.5 \%$ Triton X-100 (Boster, Wuhan, China) at room temperature for $40 \mathrm{~min}$ to permeabilize the cells and block nonspecific interactions, followed by incubation with the primary antibodies (Epitomics) of OCT4 (1:250), SOX2 (1:100), and NANOG (1:100) overnight at $4^{\circ} \mathrm{C}$. After being rinsed in phosphate buffered saline (PBS), the cells were incubated in fluorescein isothiocyanate-conjugated goat anti-rabbit $\operatorname{IgG}(\mathrm{H}+\mathrm{L})$ (1:100) (Jackson ImmunoResearch) in dark conditions for $1 \mathrm{~h}$. Following this, 4',6-diamidino-2-phenylindole (DAPI) (Boster) was used to stain the cell nuclei.

Proliferation assay. The cell counting kit-8 (CCK-8) (Dojindo Laboratories, Kumamoto, Japan) was used to evaluate the cell proliferation according to the manufacturer's instructions. To assess the influence of hypoxia on proliferation, Hep-2 and AMC-HN-8 cells were cultured under $1 \% \mathrm{O}_{2}$ for $48 \mathrm{~h}$. The cells were then re-harvested and seeded in a 96-well plate at a density of 2,000 cells/well in $0.2 \mathrm{ml}$ of DMEM, supplemented with $10 \% \mathrm{FBS}$ at $21 \% \mathrm{O}_{2}$ for $120 \mathrm{~h}$. At 0, 24, 48, 72, 96 and $120 \mathrm{~h}$ after seeding, the cells were tested for their proliferation capacities using CCK-8. The results were compared with the cells maintained consistently at $21 \% \mathrm{O}_{2}$, all the CCK-8 incubations lasted $3.5 \mathrm{~h}$ at $37^{\circ} \mathrm{C}$. Each sample in the group was repeated in 6 wells, while the medium alone (without cells) served as the blank control. The ultraviolet absorbance was measured at $450 \mathrm{~nm}$.

Matrigel invasion assay. The invasion assay was performed using 24-well transwell chambers (pore size, $8 \mu \mathrm{m}$ ) (Corning Inc., Corning, NY, USA) coated with Matrigel (BD Biosciences, Bedford, MA, USA) (1:8 dilution in serum-free medium). After being maintained under $1 \% \mathrm{O}_{2}$ for $48 \mathrm{~h}$, harvested $2 \times 10^{4} \mathrm{Hep}-2$ and AMC-HN-8 cells were suspended in $200 \mu \mathrm{l}$ of serum-free DMEM and plated in the upper chamber. The lower chamber was filled with DMEM $(600 \mu \mathrm{l})$ supplemented with $10 \% \mathrm{FBS}$, and the plates were then incubated at $21 \% \mathrm{O}_{2}$ for $24 \mathrm{~h}$. The cells on the top membrane surface were removed with a cotton swab, and those cells that migrated through the Matrigel were fixed with methanol for $15 \mathrm{~min}$, stained with $0.1 \%$ crystal violet 
Table I. Primer sequences used for qRT-PCR and chromosomal location.

\begin{tabular}{|c|c|c|c|c|}
\hline Gene & Primer Sequence $\left(5^{\prime} \rightarrow 3^{\prime}\right)$ & Accession no. & Product (bp) & Location \\
\hline OCT4 & $\begin{array}{l}\text { F: GTATTCAGCCAAACGACCAT } \\
\text { R: CTTCCTCCACCCACTTCT }\end{array}$ & NM_001173531 & 100 & $6 \mathrm{p} 21.31$ \\
\hline SOX2 & $\begin{array}{l}\text { F: TGTCAAGGCAGAGAAGAG } \\
\text { R: AGAGGCAAACTGGAATCA }\end{array}$ & NM_003106 & 223 & $3 q 26.3-q 27$ \\
\hline NANOG & $\begin{array}{l}\text { F: CTATAACTGTGGAGAGGAAT } \\
\text { R: AGTGGTCTGCTGTATTAC }\end{array}$ & NM_024865 & 124 & $12 \mathrm{p} 13.31$ \\
\hline HIF- $1 \alpha$ & $\begin{array}{l}\text { F: AGTGTACCCTAACTAGCCGAGGAA } \\
\text { R: CTGAGGTTGGTTACTGTTGGTATCA }\end{array}$ & NM_001243084 & 113 & $14 \mathrm{q} 23.2$ \\
\hline HIF- $2 \alpha$ & $\begin{array}{l}\text { F: ATGGTAGCCCTCTCCAACAAG } \\
\text { R: AGGTTCTTCATCCGTTTCCAC }\end{array}$ & NM_001430 & 134 & 2p21-p16 \\
\hline ACTB & $\begin{array}{l}\text { F: TGACGTGGACATCCGCAAAG } \\
\text { R: CTGGAA GTGGACAGCGAGG }\end{array}$ & NM_001101 & 205 & $7 \mathrm{p} 22$ \\
\hline
\end{tabular}

qRT-PCR, quantitative real-time polymerase chain reaction; F, forward; R, reverse.

for 15 min, rinsed with PBS, and counted by microscopy. Ten low power fields were randomly selected for counting, and the cells maintained consistently at $21 \% \mathrm{O}_{2}$ served as the control.

Sphere formation assay. The Hep-2 and AMC-HN-8 cells, after being maintained under $1 \% \mathrm{O}_{2}$ for $48 \mathrm{~h}$, were harvested and seeded at a density of 5,000 cells $/ \mathrm{ml}$ at $21 \% \mathrm{O}_{2}$ using the StemPro NSC SFM kit (A10509-01) (Invitrogen), with serumfree medium containing DMEM/F12, $20 \mathrm{ng} / \mathrm{ml}$ fibroblast growth factor, and $20 \mathrm{ng} / \mathrm{ml}$ epidermal growth factor. In addition, $1 \% 200 \mathrm{mmol} / 1 \mathrm{~L}$-glutamine $(25,030)$ (Invitrogen) was added. Ten days later, the spheres (containing over 30 cells) were counted under a phase-contrast microscope. Sphere formation efficiency was calculated using the formula: sphere number/seeded cell number $\times 100 \%$. The results were compared with the cells maintained consistently at $21 \% \mathrm{O}_{2}$.

Colony forming assay. After being maintained in $1 \% \mathrm{O}_{2}$ for $48 \mathrm{~h}$, the Hep-2 and AMC-HN-8 cells were harvested and seeded in 6-well plates at a density of 300 cells/well. The plates were then placed in an incubator with $21 \% \mathrm{O}_{2}$ for two weeks, after which the samples were washed twice with PBS, fixed in methanol for $15 \mathrm{~min}$, and stained with $0.1 \%$ crystal violet for $15 \mathrm{~min}$. The dye was gently washed out with PBS, and the clones containing over 50 cells were counted. Colony formation efficiency was calculated using the formula: colony number $/ 300 \times 100 \%$. The cells maintained consistently at $21 \% \mathrm{O}_{2}$ served as a control.

Statistical analysis. Data are reported as mean \pm standard deviation (SD) of at least three independent experiments. The GraphPad Prism software version 5.00 for Windows (GraphPad Software, San Diego, CA, USA) was used for data analysis. The statistical analysis was performed using the Student's t-test, and a p-value of $<0.05$ was considered to be statistically significant.

\section{Results}

Influence of hypoxia on the cell cycle. The cell cycle detection showed that exposure to $1 \% \mathrm{O}_{2}$ for $24 \mathrm{~h}$ resulted in significantly expanded G0/G1 phase cells in the Hep-2 and AMC-HN-8 cells, compared with the cells maintained at $21 \% \mathrm{O}_{2}$, whereas, the cells in the $\mathrm{S}$ and $\mathrm{G} 2 / \mathrm{M}$ phases were markedly reduced (Fig. 1A-C).

Preferential expression of laryngeal CSC marker under hypoxia. Detection by flow cytometry revealed that exposure to $1 \% \mathrm{O}_{2}$ for $48 \mathrm{~h}$ resulted in a significantly increased percentage of $\mathrm{CD}_{133^{+}} \mathrm{Hep}-2$ cells, from $1.59 \pm 0.58 \%$ to $4.45 \pm 0.75 \%$. The percentage of $\mathrm{CD} 133^{+} \mathrm{AMC}-\mathrm{HN}-8$ cells also increased from $0.47 \pm 0.14 \%$ to $1.20 \pm 0.11 \%$ (Fig. $2 \mathrm{~A}-\mathrm{C}$ ).

Upregulated mRNA level of stem cell genes under hypoxia. The qRT-PCR assay showed that the Hep-2 and AMC-HN-8 cells manifested an increased mRNA expression of OCT4, SOX2 and NANOG after being exposed to $1 \% \mathrm{O}_{2}$ for $6 \mathrm{~h}$. The mRNA expression reached the highest level at 12 or $24 \mathrm{~h}$ (Fig. 3A and B).

Elevated protein level of stem cell genes under hypoxia. The increased mRNA expression of OCT4, SOX2 and NANOG in the hypoxia-treated cells was confirmed using the western blot. Although the hypoxia-treated cells showed gradually increased protein levels starting at $12 \mathrm{~h}$, striking differences were observed at $24 \mathrm{~h}$, which was delayed compared to the mRNA expression. Furthermore, most of the proteins reached the highest expression level at $48 \mathrm{~h}$, which was also delayed when compared with the highest mRNA level (Fig. 3C and D).

Enhanced immunochemical staining of stem cell genes under hypoxia. The protein expression of OCT4, SOX2 and NANOG was also detected by immunocytochemistry. The 

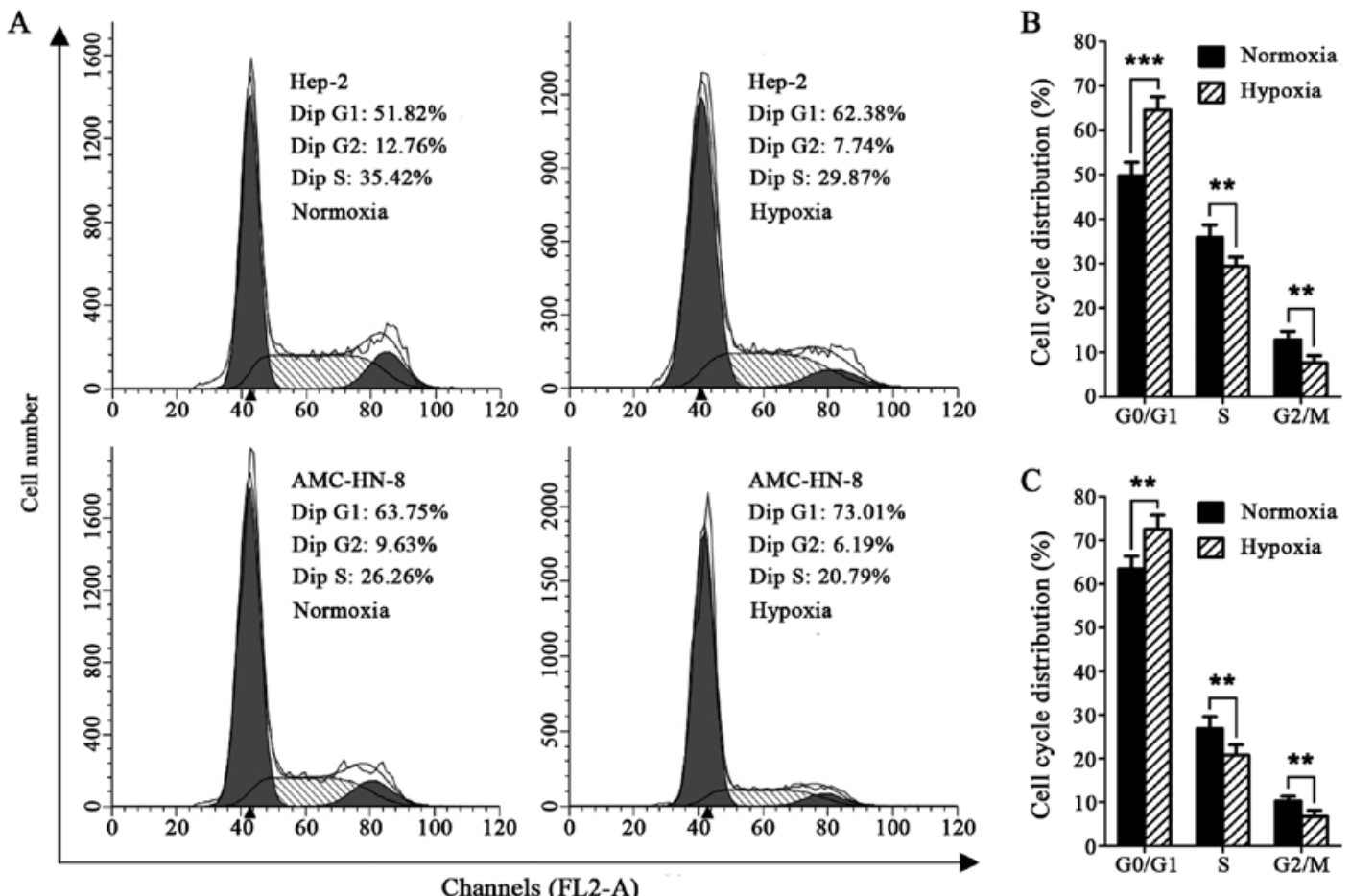

Figure 1. Influence of hypoxia on cell cycle distribution. (A) Exposure to $1 \% \mathrm{O}_{2}$ for $24 \mathrm{~h}$ resulted in significantly expanded G0/G1 phase cells in Hep-2 $(50.8 \pm 4.2 \% \rightarrow 63.17 \pm 3.9 \%)$ and AMC-HN-8 $(63.1 \pm 4.5 \% \rightarrow 74.4 \pm 4.1 \%)$ cells compared to cells maintained at $21 \% \mathrm{O}_{2}$, with decreased cells in the $\mathrm{S}$ and $\mathrm{G} 2 / \mathrm{M}$ phases Statistical analysis of cell cycle distribution of (B) Hep-2 and (C) AMC-HN-8 cells. Values are means of three experiments. All data are presented as the mean $\pm \mathrm{SD}\left({ }^{*} \mathrm{p}>0.05,{ }^{* *} \mathrm{p}<0.05,{ }^{* * *} \mathrm{p}<0.01\right)$.

A

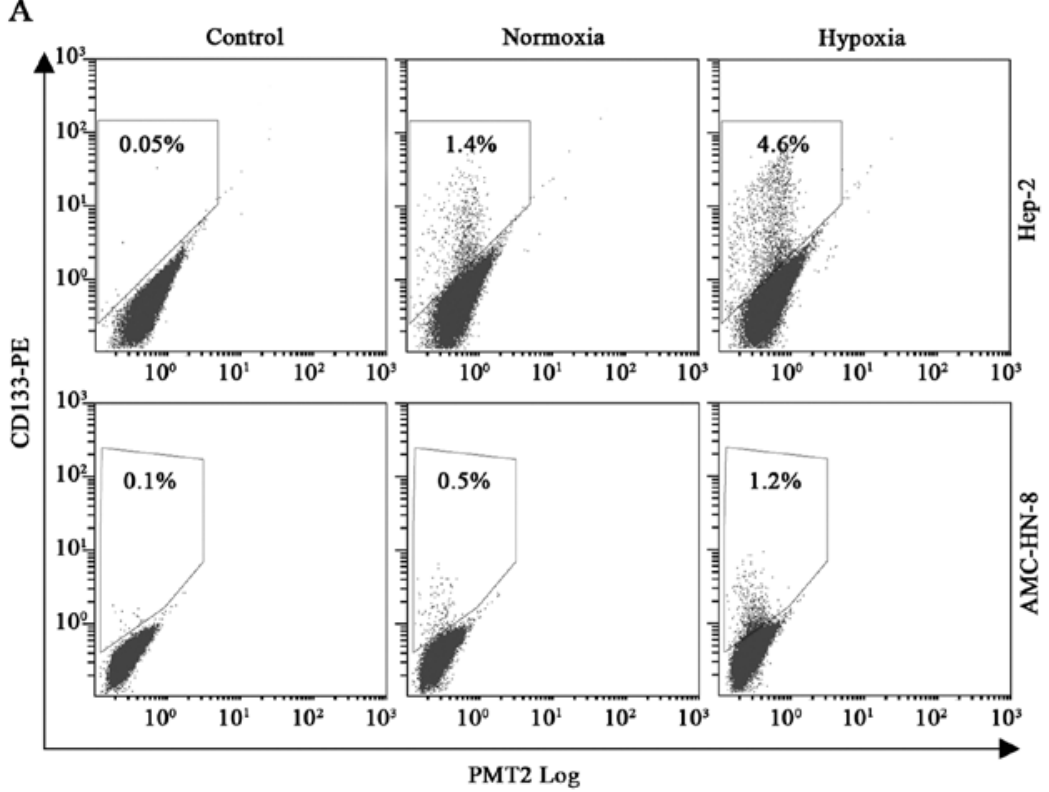

B

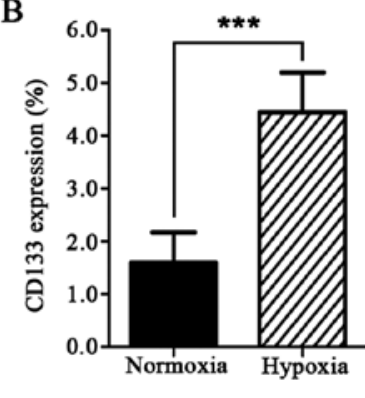

$\mathrm{C}$

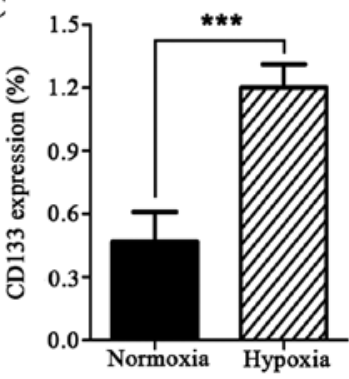

Figure 2. Influence of hypoxia on CD133 marker expression. (A) Hypoxia increased CD133 expression of Hep-2 and AMC-HN-8 cells. Statistical analysis of CD133 expression in (B) Hep-2 and (C) AMC-HN-8 cells. Values are means of three experiments. All data are presented as the mean \pm SD $\left(^{* * *} p<0.01\right)$.

Hep-2 and AMC-HN-8 cells treated with hypoxia for $48 \mathrm{~h}$ showed enhanced staining of OCT4, SOX2 and NANOG (to different extents) compared to the normoxia treated control cells (Fig. 3E and F).

Hypoxia treatment followed by normoxia exposure (HTFNE) exhibits upgraded proliferation and invasion capacity.
Although the Hep-2 and AMC-HN-8 cells maintained consistently under hypoxia grew slower than those maintained under normoxia in the first $48 \mathrm{~h}$, the hypoxia-treated cells followed by normoxia exposure grew faster than the control cells cultured consistently under normoxia (Fig. 4A and $\mathrm{B}$ ). The transwell assay showed that both the hypoxiatreated Hep-2 and AMC-HN-8 cells, when brought back 
A

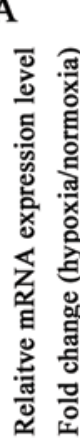

Hep-2 cell line

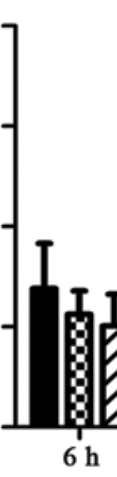

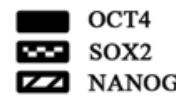

C

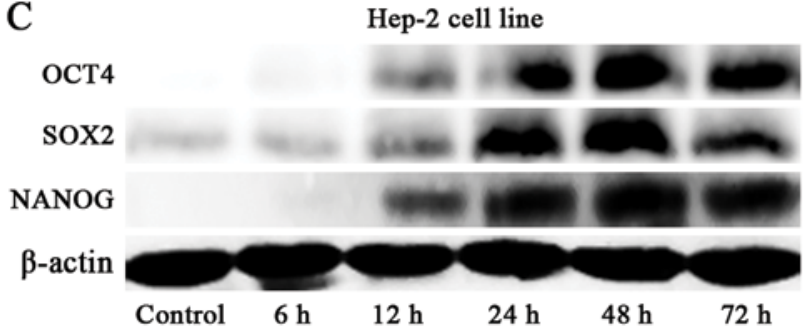

E
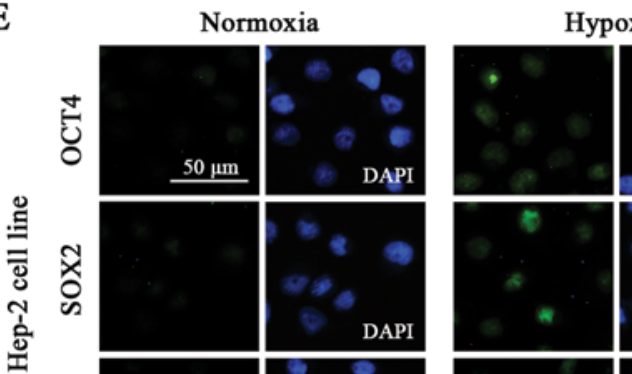

Hypoxia

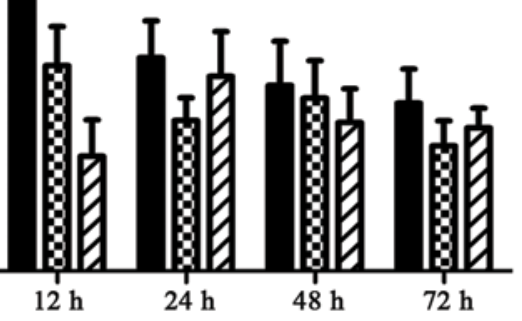

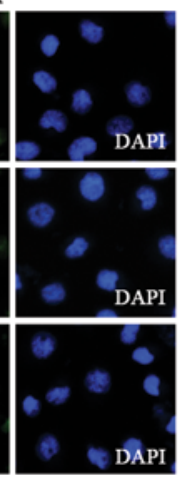

B

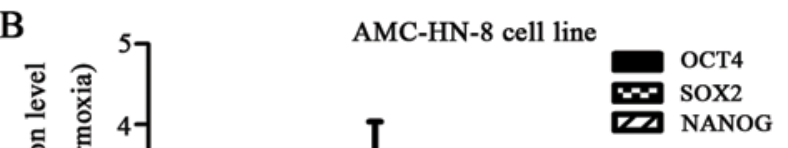

D

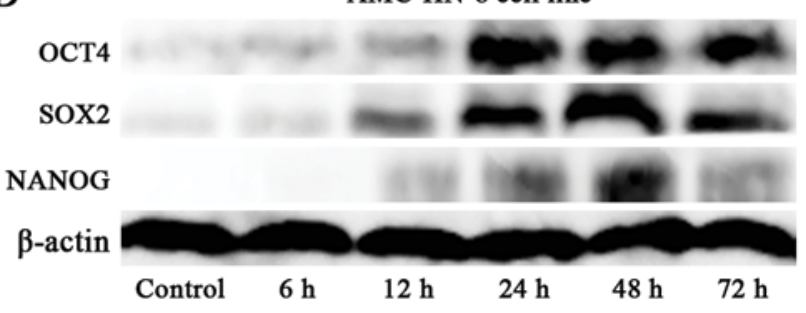

F
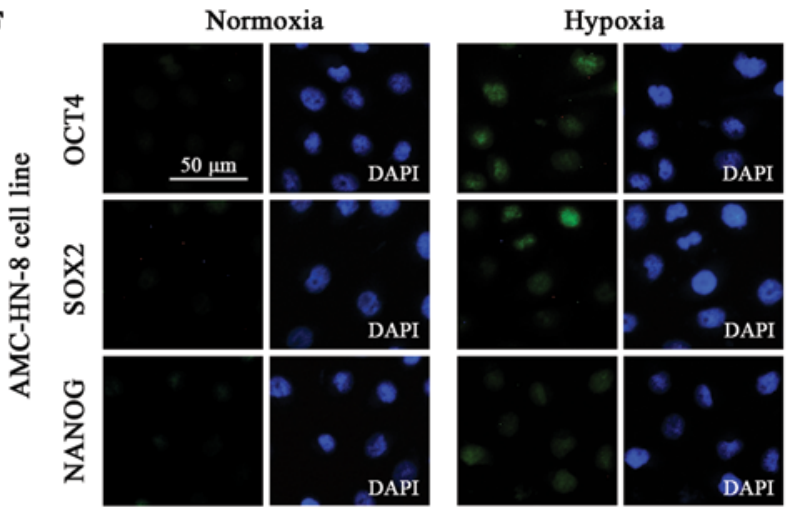

Figure 3. Hypoxia increases the expression of stem cell genes at both mRNA and protein levels. The (A) Hep-2 and (B) AMC-HN-8 cells manifested increased mRNA expression of OCT4, SOX2 and NANOG after being exposed to $1 \% \mathrm{O}_{2}$ for $6 \mathrm{~h}$, with the mRNA expression reaching the highest level at 12 or $24 \mathrm{~h}$. The (C) Hep-2 and (D) AMC-HN-8 cells maintained under hypoxia also manifested elevated protein levels of OCT4, SOX2 and NANOG compared with the control cells maintained under normoxia. Hypoxia also resulted in enhanced immunochemical staining of OCT4, SOX2 and NANOG in (E) Hep-2 and (F) AMC-HN-8 cells. Values are means of three experiments. All data are presented as the mean \pm SD.

to normoxia, had a significantly increased number of cells migrating across the Matrigel compared to the control cells (Fig. 4C and D).

HTFNE presents enhanced sphere and colony formation capability. In the sphere formation assay, when compared with the cells maintained under normoxia, more spheres were observed in both the hypoxia treated cell lines followed by normoxia exposure (Fig. 5A and C). Furthermore, the hypoxia treated cells, when brought back to normoxia, formed more colonies than the control cells, with a 1.7-fold increase in the Hep- 2 cells and a 1.9-fold increase in the AMC-HN-8 cells, respectively (Fig. 5B and D).

Hypoxia upregulates HIFs. The Hep-2 and AMC-HN-8 cells manifested increased mRNA expressions of HIF-1 $\alpha$ and HIF-2 $\alpha$ after being exposed to hypoxia for $6 \mathrm{~h}$, and the mRNA expression reached the highest level at 12 or $24 \mathrm{~h}$. Both of the two cell lines cultured under hypoxia for $48 \mathrm{~h}$ showed significantly enhanced protein levels of HIF-1 $\alpha$ and HIF- $2 \alpha$ compared with the control cells. The elevation of HIF-1 $\alpha$ was greater than that of HIF- $2 \alpha$ in both mRNA and protein levels (Fig. 6).

\section{Discussion}

It is widely accepted that cancer cells are hypoxic in solid tumors when compared to normal tissue because the microcirculation is compromised and tissue oxygenation is not regulated according to metabolic demand. Hypoxia is an inherent feature of solid tumors, and when the tumor volume reaches $2 \mathrm{ml}$, the oxygen tension could be close to $0 \mathrm{mmHg}$ (18). Recent studies show that hypoxia, as a critical component of the tumor microenvironment, can directly regulate the stem-like properties of CSCs in ways such as selfrenewal, differentiation, migration and invasion, colony and sphere formation, and therapeutic resistance $(12-14,19)$. In this study, we investigated whether hypoxia is able to regulate the stem-like biological properties of laryngeal cancer cells and discussed the possible mechanisms involved. 
A

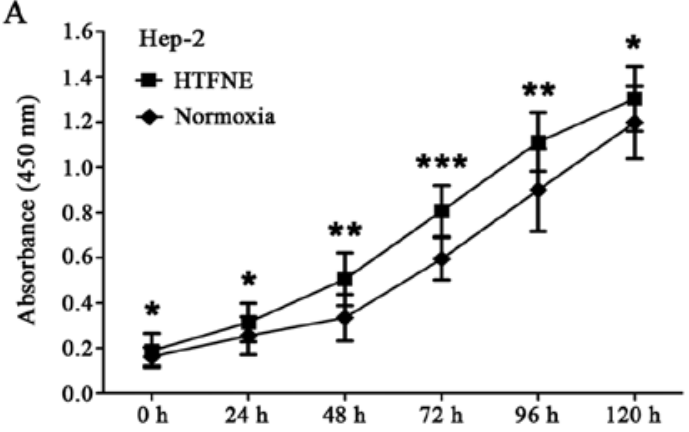

c
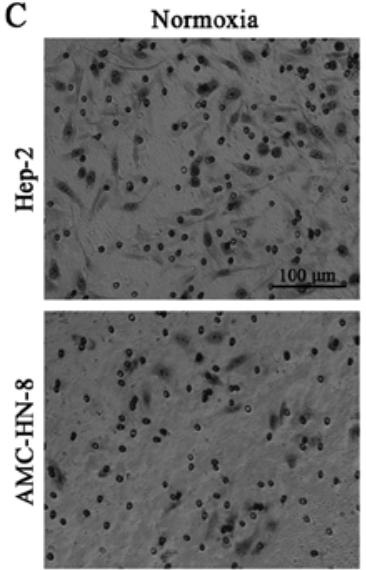
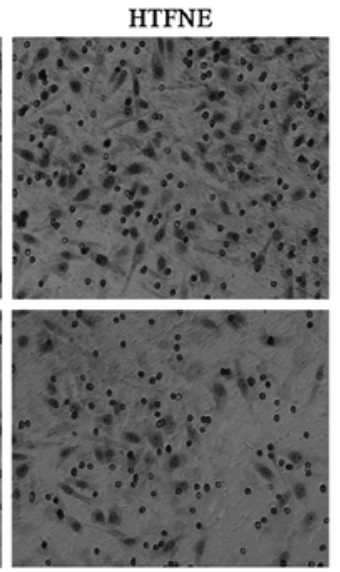

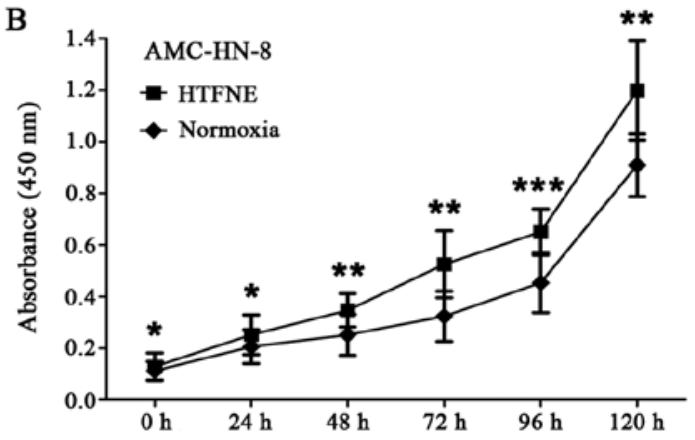

D

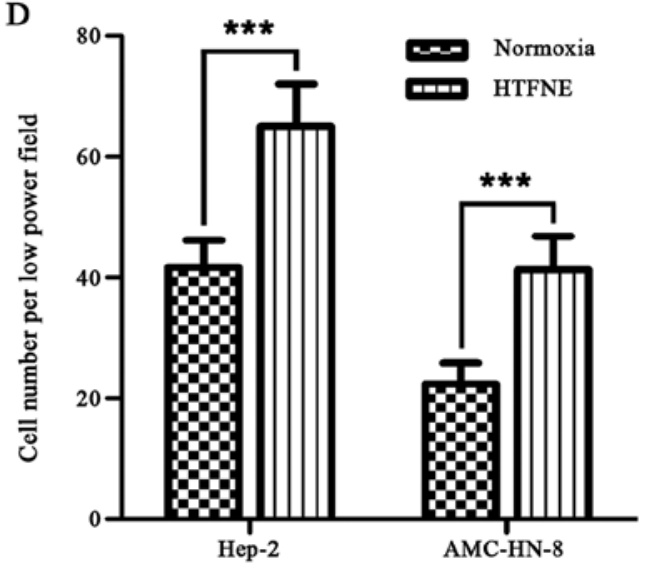

Figure 4. HTFNE exhibits upgraded proliferation and invasion capacity. After being cultured for $48 \mathrm{~h}$ at $1 \% \mathrm{O}_{2}$, the hypoxia-treated (A) Hep-2 and (B) AMCHN-8 cells followed by normoxia exposure grew faster than those control cells cultured consistently under normoxia. The hypoxia-treated Hep-2 and AMC-HN-8 cells followed by normoxia exposure also manifested a significantly higher capacity for invasion in the (C) Transwell assay, and (D) statistical analysis $\left({ }^{*} \mathrm{p}>0.05,{ }^{* *} \mathrm{p}<0.05,{ }^{* * *} \mathrm{p}<0.01\right)$. Values are means of three experiments. All data are presented as the mean \pm SD.

The transient and long-term quiescence (G0/G1 phase in cell cycle) are generally believed to be fundamental features of stem cells (20). On the basis of this premise, we analyzed the cell cycle distribution of the cells cultured under hypoxia, and found that both the Hep-2 and AMC-HN-8 cell lines exhibited significantly expanded G0/G1 phases and reduced $\mathrm{S}$ and $\mathrm{G} 2 / \mathrm{M}$ phases after being exposed to hypoxia for $24 \mathrm{~h}$ (Fig. 1A-C), consistent with the previous studies that hypoxia can invert the vigorously divided cancer cells into a quiescent state $(21,22)$, which is one of the inherent features of CSCs.

We subsequently focused on the expression of CD133, the CSC marker of laryngeal cancer cells identified in our previous investigations (15-17), in the hypoxia-exposed cancer cells. We found that exposure to $1 \% \mathrm{O}_{2}$ for $48 \mathrm{~h}$ resulted in increased CD133 expression, 2.8 -fold increase in the Hep-2 cell line and 2.5-fold increase in the AMC-HN-8 cell line (Fig. 2A-C), in line with the previous studies on pancreatic cancer (23), glioma (24), and ovarian cancer (13). The hypoxia-induced expansion of $\mathrm{CD} 133^{+} \mathrm{CSC}$ subpopulation may reasonably explain the enhanced stem-like properties of laryngeal cancer cells in the subsequent investigation.

Evidence from different experimental systems has shown that some transcriptional factors are critical participants in the regulation of self-renewal and differentiation of stem cells, such as OCT4 (25), SOX2 (26), and NANOG (27), and manipulating the expression of OCT4 and SOX2 contribute to the induction of pluripotent stem cells from differentiated mouse/human fibroblasts $(28,29)$. In addition, hypoxia is reported to influence the expression of a panel of stem cell transcriptional factors (30). In this study, we also found that the Hep-2 and AMC-HN-8 cells began to show increased mRNA expression of OCT4, SOX2 and NANOG after being exposed to $1 \% \mathrm{O}_{2}$ for $6 \mathrm{~h}$, and the mRNA expression reached the highest level at 12 or $24 \mathrm{~h}$ (Fig. 3A and B). Furthermore, we verified the upregulation of these three genes by using the western blot and immunofluorescence staining. In the western blot assay, we found a striking elevation in protein expression at $24 \mathrm{~h}$ and the highest protein level at $48 \mathrm{~h}$, both of which were delayed compared to the changes at the mRNA level (Fig. 3C and D). We also found enhanced immunofluorescence staining of OCT4, SOX2 and NANOG (to different extents) compared with the control cells (Fig. 3E and F). These findings were in agreement with previous studies (12-14), indicating that the influence of hypoxia on the stem-like property may be exerted through changes in the expression of these stem cell transcriptional factors.

Since hypoxia influenced the stem cell phenotypes, such as the quiescent status and expression of stem cell genes and laryngeal CSC marker, we then focused on whether hypoxia could influence the stem-like biological behavior of these cell lines. To our disappointment, we found that these two cell lines maintained consistently under hypoxia did not exhibit significantly enhanced stem-like biological properties, such as proliferation, invasion, and sphere/colony formation (data not shown), than the cells maintained consistently under normoxia. Such phenomenon was also reported by Liang et al in ovarian 
A
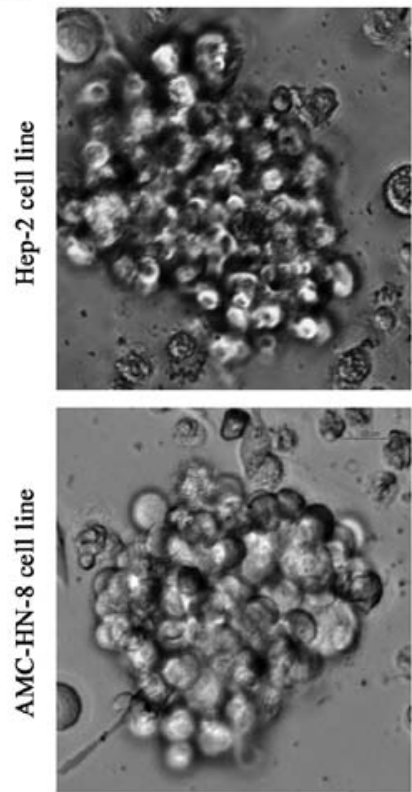

C

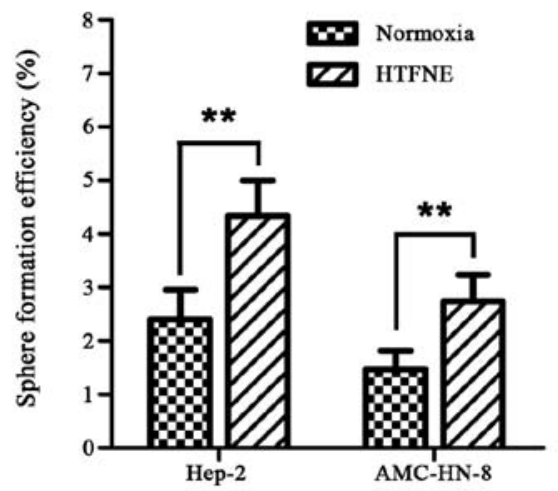

B
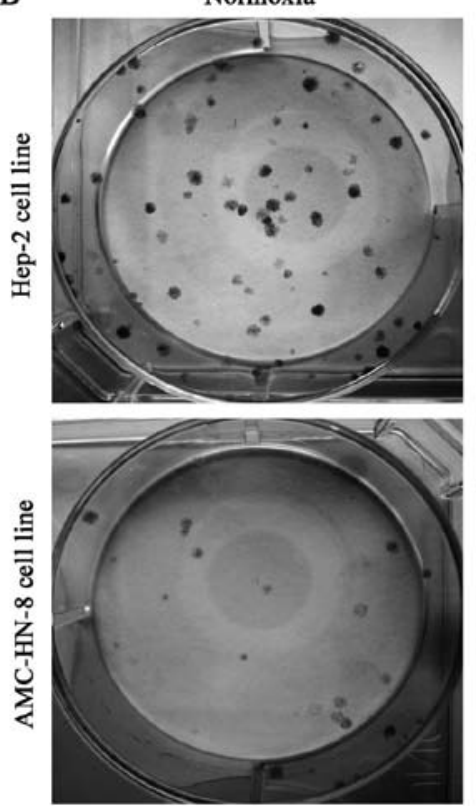

D
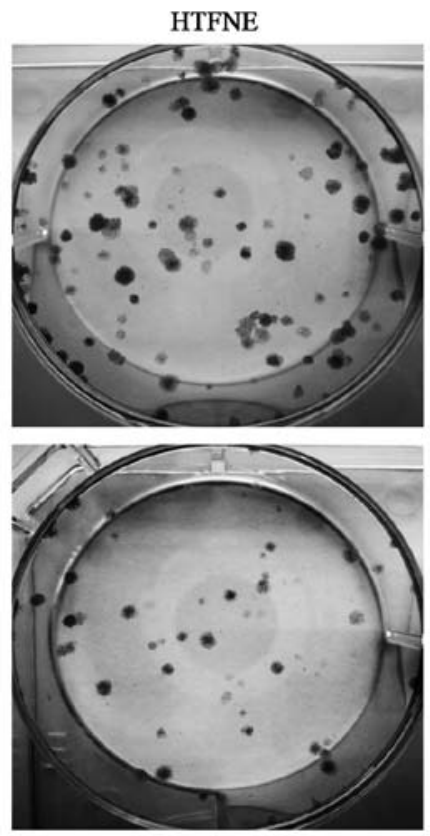

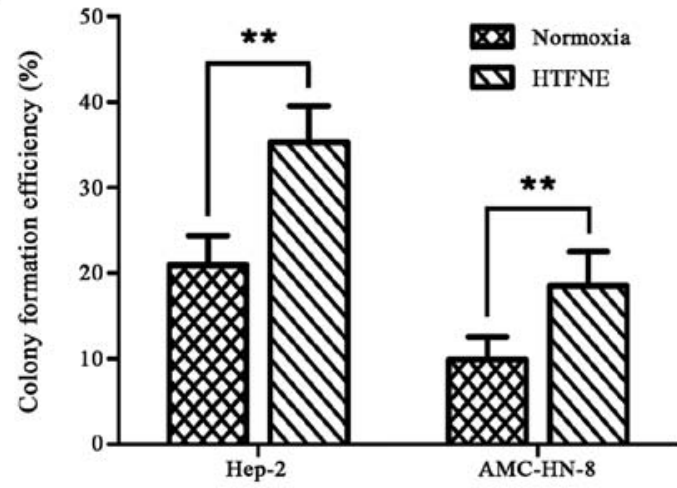

Figure 5. HTFNE presents enhanced sphere and colony formation potential. (A) Representative spheres formed by hypoxia-treated Hep-2 and AMC-HN-8 cells followed by normoxia exposure and (C) statistical analysis of sphere formation efficiency. (B) Colony formation assay showed more colonies in the hypoxia-treated Hep-2 and AMC-HN-8 cells followed by normoxia exposure and (D) statistical analysis of colony formation efficiency $\left({ }^{* *}\right.$ p $\left.<0.05\right)$. Values are means of three experiments. All data are presented as the mean $\pm \mathrm{SD}$.
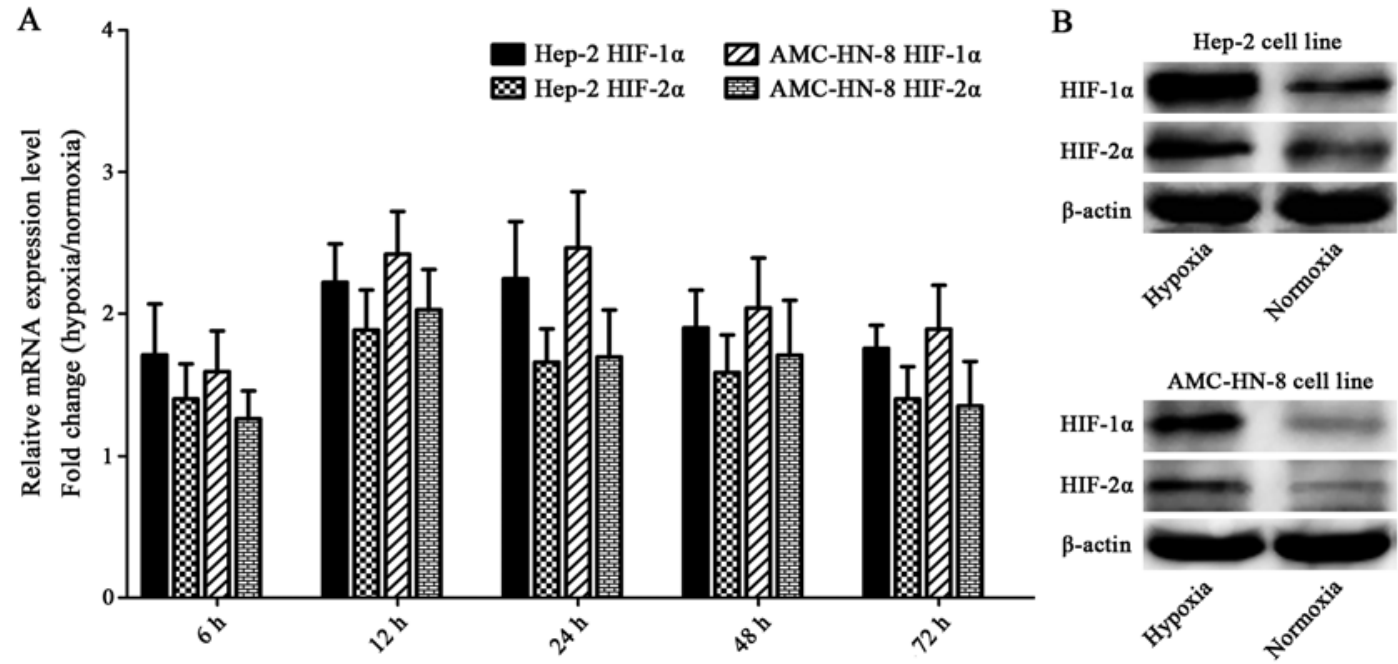

Figure 6. Hypoxia upregulates HIFs. (A) The Hep-2 and AMC-HN-8 cells showed increased mRNA expression of HIF-1 $\alpha$ and HIF-2 $\alpha$ after being exposed to $1 \% \mathrm{O}_{2}$ for $6 \mathrm{~h}$, and the mRNA expression reaches the highest level at 12 or $24 \mathrm{~h}$. (B) Western blotting showed that the two cell lines maintained under hypoxia for $48 \mathrm{~h}$ manifested elevated protein levels of HIF-1 $\alpha$ and HIF- $2 \alpha$ compared with the cells maintained under normoxia. The elevation of HIF-1 $\alpha$ was greater than that of HIF-2 $\alpha$ in both mRNA and protein levels. Values are means of three experiments. All data are presented as the mean \pm SD. 
cancer research; however, they further observed that hypoxiatreated ovarian cancer cells behave more aggressively when brought back to higher oxygen environment (13). Enlightened by their findings, we then investigated whether hypoxia treatment followed by normoxia exposure could help us visualize the enhanced biological stemness induced by hypoxia.

In the proliferation assay, we found that the hypoxia treated laryngeal cancer cells, when brought back to normoxia, propagated significantly faster compared to the cells maintained under normoxia (Fig. 4A and B). Additionally, we observed that when brought back to normoxia, the hypoxia treated laryngeal cancer cells exhibited significantly higher capacity for invasion (Fig. 4C and D) and colony and sphere formation (Fig. 5) when compared to the cells maintained consistently under hypoxia. These results indicated that hypoxia did exert an important influence on the stem-like properties of laryngeal cancer cells. However, the enhanced stemness may be classified into two categories: the first one is static, such as expanded G0/G1 phase and upregulated CSCs marker and stem cell genes, which can be directly measured by using cells cultured consistently under hypoxia; the second one is dynamics, such as enhanced stem-like biological behavior of proliferation, invasion and sphere/colony formation, which can only be visualized by bringing the hypoxia-cultured cells back to normoxia. This characteristic is reminiscent of tumor metastasis, where invasive cancer cells migrated into the blood vessel (sudden exposure to higher oxygen stress compared with the hypoxic tumor microenvironment), and may exhibit more aggressive biological properties.

Since we have verified that hypoxia upregulates the stem cell transcriptional factors (OCT4, SOX2 and NONOG) of Hep-2 and AMC-HN-8 cells to different extent, which may contribute to the expansion of CD133+ laryngeal CSC subpopulation because a recent study revealed that hypoxiainduced OCT4 and SOX2 upregulate CD133 expression by directly binding to the P1 promoter (31). Next we investigated the possible mechanism whereby hypoxia regulated these transcriptional factors. A previous study shows that HIF- $2 \alpha$ specifically regulates the expression of OCT4 by directly binding to its promoter, which identifies OCT4 as a HIF-2 $\alpha$ specific target gene (32). In contrast, there are still no reports suggesting that SOX2 and NANOG are direct (or indirect) HIFs targets, although it is certainly possible. However, it has been shown that it is through HIFs that hypoxia induces the expression of pluripotent stem cell inducers, OCT4, NANOG, SOX2, KLF4 and MYC, in 11 cancer cell lines, although the exact mechanism remains to be clarified (33), indicating that NANOG and SOX2 are also direct or indirect target genes of HIFs. Therefore, next we investigated the expression changes of HIFs.

We found that the expression of both HIF-1 $\alpha$ and HIF-2 $\alpha$ was elevated in Hep- 2 and AMC-HN-8 cells upon hypoxia exposure, and the elevation of HIF-1 $\alpha$ was greater than that of HIF-2 $\alpha$ (Fig. 6), indicating that although both HIF-1 $\alpha$ and HIF- $2 \alpha$ are involved in the regulation of laryngeal CSCs, HIF-1 $\alpha$ may dominate. These findings may be helpful in explaining the relevant results from our recent study (34) where HIF-1 $\alpha$ was highly expressed in laryngeal cancer tissues and significantly related to the clinical stage and lymph node metastasis, a possible explanation may be that advanced and metastatic cancer tissues contained a larger proportion of CSCs.

However, the relative importance of HIF-1 $\alpha$ and HIF- $2 \alpha$ in CSC maintenance varies in different cancer types. It has been reported that HIF- $2 \alpha$ maintains the undifferentiated and aggressive phenotype of neuroblastoma CSCs (35). However, Soeda et al showed that it is mainly through HIF-1 $\alpha$ that hypoxia regulates the in vitro self-renewal and differentiation of glioma CSCs (24). Although much remains to be clarified, our findings solidify the central concept that hypoxia-induced HIFs contribute to the maintenance of the CSC phenotype by directly or indirectly regulating the stem cell transcriptional factors.

Since hypoxia does not occur early in tumors, the hypoxiainduced influence on cancer cells often results in poor prognosis for cancer patients and resistance to radiotherapy and chemotherapy, which has been validated by increasing studies (36-38). However, the exact mechanism may vary in different cancer types and remains to be clarified.

In conclusion, our observations demonstrate that the hypoxic microenvironment may upgrade the stem-like biological properties of laryngeal cancer cell lines by increasing the $\mathrm{CD}_{133^{+}}$stem cell fraction. The most possible mechanism may be the HIFs-induced upregulation of OCT4, SOX2 and NANOG, which then directly bind to the CD133 promoter 1 and induce its expression. This hypothesis needs further clarification. Furthermore, the hypoxia-treated laryngeal cancer cells, which acquire enhanced stemness, behave more aggressively when brought back to normoxia. However, the study of hypoxia-induced influence on laryngeal CSCs relatively lags behind other solid tumors, such as prostate cancer and breast cancer, and we are still in the early stages of understanding the exact mechanism by which hypoxia maintains and regulates the laryngeal CSCs. Further studies are needed to accelerate the pace of research on hypoxiaregulated CSCs in laryngeal cancer.

\section{Acknowledgements}

We would like to thank Yan-Ping Zhang for her assistance in the molecular biology experiments. This study was partially funded by grants from the Shanghai Science and Technology Foundation of China (12JC1402101) and the Ming Dao Doctoral Sustentation Fund of Fudan University.

\section{References}

1. Visvader JE and Lindeman GJ: Cancer stem cells in solid tumours: accumulating evidence and unresolved questions. Nat Rev Cancer 8: 755-768, 2008.

2. Akhtar K, Bussen W and Scott SP: Cancer stem cells - from initiation to elimination, how far have we reached? (Review). Int J Oncol 34: 1491-1503, 2009.

3. Bhaijee F, Pepper DJ, Pitman KT and Bell D: Cancer stem cells in head and neck squamous cell carcinoma: a review of current knowledge and future applications. Head Neck 34: 894-899, 2012.

4. Sneddon JB and Werb Z: Location, location, location: the cancer stem cell niche. Cell Stem Cell 1: 607-611, 2007.

5. Borovski T, De Sousa E Melo F, Vermeulen L and Medema JP: Cancer stem cell niche: the place to be. Cancer Res 71: 634-639, 2011.

6. Takakura N: Formation and regulation of the cancer stem cell niche. Cancer Sci 103: 1177-1181, 2012.

7. Keith B and Simon MC: Hypoxia-inducible factors, stem cells, and cancer. Cell 129: 465-472, 2007. 
8. Sun QJ, Li XM, Lu XY and Di B: Cancer stem cells may be mostly maintained by fluctuating hypoxia. Med Hypotheses 76: 471-473, 2011

9. Lin Q and Yun Z: Impact of the hypoxic tumor microenvironment on the regulation of cancer stem cell characteristics. Cancer Bio Ther 9: 949-956, 2010.

10. Hill RP, Marie-Egyptienne DT and Hedley DW: Cancer stem cells, hypoxia and metastasis. Semin Radiat Oncol 19: 106-111, 2009.

11. Conley SJ, Gheordunescu E, Kakarala P, et al: Antiangiogenic agents increase breast cancer stem cells via the generation of tumor hypoxia. Proc Natl Acad Sci USA 109: 2784-2789, 2012.

12. Ma YY, Liang DM, Liu J, et al: Prostate cancer cell lines under hypoxia exhibit greater stem-like properties. PLoS One 6 : e29170, 2011.

13. Liang DM, Ma YY, Liu J, Trope CG, Holm R, Nesland JM and Suo ZH: The hypoxic microenvironment upgrades stem-like properties of ovarian cancer cells. BMC Cancer 12: 201, 2012.

14. Li PC, Zhou C, Xu LS and Xiao HL: Hypoxia enhances stemness of cancer stem cells in glioblastoma: an in vitro study. Int J Med Sci 10: 399-407, 2013.

15. Zhou L, Wei XD, Cheng L, Tian J and Jiang JJ: CD133, one of the markers of cancer stem cells in Hep-2 cell line. Laryngoscope 117: 455-460, 2007.

16. Wei XD, Zhou L, Cheng L, Tian J, Jiang JJ and MacCallum J: In vivo investigation of CD133 as a putative marker of cancer stem cells in Hep-2 cell line. Head Neck 31: 94-101, 2009.

17. Chen H, Zhou L, Dou TH, Wan GL, Tang HQ and Tian J: BMIl's maintenance of the proliferative capacity of laryngeal cancer stem cells Head Neck 33: 1115-1125, 2011.

18. Guppy M: The hypoxic core: a possible answer to the cancer paradox. Biochem Biophys Res Commun 299: 676-680, 2002.

19. Tsujinaka S, Soda K, Kano Y and Konishi F: Spermine accelerates hypoxia-initiated cancer cell migration. Int $\mathrm{J}$ Oncol 38 : 305-312, 2011

20. Clevers H: The cancer stem cell: premises, promises and challenges. Nat Med 17: 313-319, 2011.

21. Yoshiba S, Ito D, Nagumo T, Shirota T, Hatori M and Shintani S: Hypoxia induces resistance to 5-fluorouracil in oral cancer cells via G(1) phase cell cycle arrest. Oral Oncol 45: 109-115, 2009.

22. Box AH and Demetrick DJ: Cell cycle kinase inhibitor expression and hypoxia-induced cell cycle arrest in human cancer cell lines Carcinogenesis 25: 2325-2335, 2004.

23. Hashimoto O, Shimizu K, Semba S, Chiba S, Ku Y, Yokozaki H and Hori Y: Hypoxia induces tumor aggressiveness and the expansion of CD133-positive cells in a hypoxia-inducible factor-1alpha-dependent manner in pancreatic cancer cells. Pathobiology 78: 181-192, 2011.

24. Soeda A, Park M, Lee D, et al: Hypoxia promotes expansion of the CD133-positive glioma stem cells through activation of HIF-1alpha. Oncogene 28: 3949-3959, 2009.
25. Shi G and Jin Y: Role of Oct4 in maintaining and regaining stem cell pluripotency. Stem Cell Res Ther 1: 39, 2010.

26. Schmidt $\mathrm{R}$ and Plath $\mathrm{K}$ : The roles of the reprogramming factors Oct4, Sox 2 and Klf4 in resetting the somatic cell epigenome during induced pluripotent stem cell generation. Genome Biol 13: 251,2012 .

27. Luo W, Li S, Peng B, Ye Y, Deng X and Yao K: Embryonic stem cells markers SOX2, OCT4 and Nanog expression and their correlations with epithelial-mesenchymal transition in nasopharyngeal carcinoma. PLoS One 8: e56324, 2013.

28. Takahashi K and Yamanaka S: Induction of pluripotent stem cells from mouse embryonic and adult fibroblast cultures by defined factors. Cell 126: 663-676, 2006.

29. Huangfu D, Osafune K, Maehr R, et al: Induction of pluripotent stem cells from primary human fibroblasts with only Oct 4 and Sox2. Nat Biotechnol 26: 1269-1275, 2008.

30. Kolenda J, Jensen SS, Aaberg-Jessen C, Christensen K, Andersen C, Brunner N and Kristensen BW: Effects of hypoxia on expression of a panel of stem cell and chemoresistance markers in glioblastoma-derived spheroids. J Neurooncol 103: 43-58, 2011.

31. Iida H, Suzuki M, Goitsuka R and Ueno H: Hypoxia induces CD133 expression in human lung cancer cells by up-regulation of OCT3/4 and SOX2. Int J Oncol 40: 71-79, 2012.

32. Covello KL, Kehler J, Yu H, et al: HIF-2alpha regulates Oct-4: effects of hypoxia on stem cell function, embryonic development, and tumor growth. Genes Dev 20: 557-570, 2006.

33. Mathieu J, Zhang Z, Zhou W, et al: HIF induces human embryonic stem cell markers in cancer cells. Cancer Res 71: 4640-4652, 2011.

34. Li DW, Zhou L, Jin B, Xie J and Dong P: Expression and significance of hypoxia-inducible factor-1alpha and survivin in laryngeal carcinoma tissue and cells. Otolaryngol Head Neck Surg 148: 75-81, 2013.

35. Pietras A, Hansford LM, Johnsson AS, et al: HIF-2alpha maintains an undifferentiated state in neural crest-like human neuroblastoma tumor-initiating cells. Proc Natl Acad Sci USA 106: 16805-16810, 2009.

36. Sun HC, Qiu ZJ, Liu J, et al: Expression of hypoxia-inducible factor-1 $\alpha$ and associated proteins in pancreatic ductal adenocarcinoma and their impact on prognosis. Int $\mathbf{J}$ Oncol 30: 1359-1367, 2007

37. Jubb AM, Buffa FM and Harris AL: Assessment of tumour hypoxia for prediction of response to therapy and cancer prognosis. J Cell Mol Med 14: 18-29, 2010.

38. Lundgren K, Holm $\mathrm{C}$ and Landberg G: Hypoxia and breast cancer: prognostic and therapeutic implications. Cell Mol Life Sci 64: 3233-3247, 2007. 